\title{
Study of The Teacher's Readiness Condition to Implement the Idea of Managing the Personal Trajectory of Professional Development Within the Framework of Digitalization of Education
}

\author{
Tatiana Zinovyeva ${ }^{1 *}$, Zhanna Afanasyeva ${ }^{1}$, Antonina Bogdanova ${ }^{1}$, and Evgeniy Leonovich ${ }^{1}$ \\ ${ }^{1}$ Moscow City Teacher Training University, Institute of Pedagogy and Psychology of Education, \\ Teaching Methods Department, Moscow, Russia
}

\begin{abstract}
The article deals with the topical issue of digitalization of education as a component of the digital transformation of contemporary society and the economy in general. The purpose of the research is to identify the readiness status of teaching staff for professional activity in the context of the digitalization of education. The main research methods were the questionnaire (implemented in the form of an online survey among students of the extramural form of study of the Moscow City Pedagogical University working at educational institutions of Moscow), and statistical analysis of the data obtained. The results of an online survey of teachers allowed concluding that today teachers have acquired a positive experience in the use of recommended tested digital educational resources, the ability to develop innovative digital educational and methodological support for the educational process, as well as recognized the need to build a personal trajectory of professional development in the framework of digital education.
\end{abstract}

\section{Introduction}

According to scientists from different countries (A. Hidalgo, A. Urueña, G. Morales-Alonso, G. Siemens, G. Veletsianos, J. Amin, J. Seaman, N. Johnson, P. Gilster, S. Gabaly), the latest trend in global social development is the implementation of the idea of digitalization in all spheres of human activity (production, business, science, social sphere, and the daily life of citizens) for their (spheres of activity) innovative transformation based on the use of digital resources and technologies [1-5].

Digitalization becomes a trend of effective global development if the digital transformation of information meets certain requirements. Among such requirements, contemporary researchers (E.J. Cumella, E. Reyes-Fournier, G. Blackman, G.V. Chernova, J. Pedersen, J.E.M. Lingat, J.R. Schmidt, J.W. Richardson, M. Pritchard, V.G. Khalin) indicate the following: first, it is in demand, available to users of different social groups (not only to professionals but also to ordinary citizens), who have the appropriate skills and

\footnotetext{
* Corresponding author: zti111@mail.ru
} 
competencies; secondly, due to the formation of integral technological environments (ecosystems, platforms), it provides the user with the opportunity to create a friendly environment (technological, instrumental, methodological, partner, etc.) necessary for solving an entire class of problems rather than a single task; and third, it makes it possible to increase the efficiency of the economy and improve the citizens' quality of life [6-9].

Researchers in the field of sociology, politics, and economics (A. Ritzhaupt, D. Hillmayr, F. Martin, F. Reinhold, G. Polizzi, I. Blau, K. Budhrani, K.M. Reiss, L. Ziernwald, O. Avdiel, S.I. Hofer, S. Kumar, T. Shamir-Inbal) highlight the problem of digitalization management at the national level as a priority task, which involves the state solving a number of important tasks, including: providing opportunities for implementing the prerequisites of digitalization as positive conditions for favorable impact on the economic and social life of the state; legal regulation, i.e. developing and implementing programs for managing the benefits of digitalization, bridging the digital divide; organizing digitalization processes based on state funding; detecting challenges, threats, problems and expected negative consequences of digitalization; as well as implementing risk management programs to increase the impact of digitalization as a trend of effective development of the world economy and society [10-13].

The progressive movement of contemporary Russia in line with global trends in digitalization is reflected in statutory and regulatory enactments. The fundamental document of the digital transformation of Russian society and economy is the "Strategy of the Information Society Development in the Russian Federation for 2017-2030" (hereinafter referred to as the Strategy), approved by presidential decree of May 9, 2017, No. 203. The Strategy provides targets aimed at implementing the domestic and foreign policy of the state in terms of the formation of the national digital economy and society to ensure national interests and implement strategic national priorities [14].

The strategy developed to implement the national program "Digital Economy of the Russian Federation" (hereinafter - the Program) is focused on "creating conditions for the development of the knowledge society, improving the welfare and citizens' quality of life "through the application of digital technology and digital literacy of citizens of the Russian Federation in all sectors of human activity $[15, \mathrm{p} .1]$. The knowledge society appears in the status of a social medium in which the main importance for the development of the citizen, the economy, and the state in general, is the possession (receipt, preservation, dissemination) of information that is reliable and significant in terms of strategic national priorities of the state.

The ambiguous situation that emerged in the education system is reflected in the section "Socio-economic conditions for the adoption of the Program". On the one hand, there are some achievements, such as increased use of digital technologies, availability of the Internet in educational institutions; while, on the other hand, certain unresolved issues are noted, namely, "the number of trained staff and compliance of educational programs to the needs of the digital economy is insufficient, there is a serious shortage of personnel in the educational process at all levels of education" [15, p. 6].

The Program section "Staff and education" provides urgent measures to overcome the current situation: providing primary conditions for training the staff of the digital economy; upgrading the education system from the standpoint of the digital economy; restructuring the labor market in the context of the digital economy needs; and creating personnel motivation system in mastering competencies in the digital economy [15, p. 11].

Achieving the target state of digital economy development in the area of "personnel" in the Program roadmap is reflected in stages: developing requirements to describe digital economy competencies (in 2018); ensuring the coordinated work of educational structures, creating a personal trajectory for the development of personnel competencies for the digital economy (in 2019); and ensuring the human potential of the digital economy and digital competence of citizens (in 2020) [15, p. 18-19]. 
The issues of readiness of teachers to implement the idea of digitalization of education in their professional activities, as a significant component of the economy and society digitalization [16; 17], as well as willingness to rethink the role and place of school teachers and university professors in the education system [18; 19] are considered in the works of contemporary researchers (E.K. Samerkhanova, E.P. Krupoderova, J.V. Afanasieva, K.R. Krupoderova, L.N. Bakhtiyarova, M.-E. Ociseanu, M. Prensky, and T.I. Zinovyeva).

\section{Methods}

The study of the readiness of teachers for professional activity in the context of digitalization of education was carried out in February 2020 in the form of an online survey among students of the Moscow City Pedagogical University working in educational institutions of Moscow. It should be noted that the leadership of the Moscow education system is currently implementing the "Digital school" project for 2018-2025, for which the original digital educational resource "Moscow electronic school" (MES) has been specially created and implemented. In the scientific description, this resource is treated as a "cloud-based Internet platform that contains a large educational content (complexes of functional blocks interconnected according to certain principles, and designed for learning, as well as tools to create them), sort of integrator of various educational resources and servers available to all participants in the educational process", i.e. teachers, students, and their parents [20, p. 20]. This suggests that the respondents in the online survey were practicing teachers, active users of innovative digital educational resources, that is, participants in the Russian education digitalization process.

\section{Results}

Analysis of the data obtained in the survey has shown that the vast majority of practicing teachers (96\%) understand the essence, focus, and interconnectedness of the informatization and digitalization processes with respect to society as its movement towards achieving the status of information, digital society, in which information, digital resources, and technologies dramatically affect the economic and social conditions of citizens contributing to improving their quality.

The implementation of the idea of digitalization in the education system is interpreted differently by teachers. A significant part of the surveyed teachers (66\%) consider the digitalization of education only as a process of filling the educational environment with innovative digital educational resources and technologies. In the understanding of another group of educators (34\% of them), the idea of digitalization of education is more or less related to the subjects of educational relations, who master the ability to solve problems arising in the educational process based on awareness of the digital educational environment.

The survey has shown that $100 \%$ of teachers were aware of the goals of the digitalization of education. Among other things they also noted the following aspects: preparing students for full-fledged participation in the everyday, social and professional life in a digital society; increasing the availability of education; integrating the national education system into the information infrastructure of the global community, etc. At that, teachers adequately identify targets of digitalization of education with the results achieved in the educational process. This concerns increasing the motivation of students to the educational process (78\%); optimizing and providing accessibility of the learning process (69\%); conducting transition from an explanatory and illustrated way of learning to activity that allows the child to become a subject of the educational activity $(42 \%)$. 
In terms of their professional activities, respondents indicated the following implemented opportunities for digitalization of education: increasing the level of digital literacy (92\%); mastering the skills of using digital resources and technologies in the educational process (89\%); improving their communication skills in the digital educational environment $(81 \%)$; increasing the level of subject-specific methodological competencies (49\%); and realizing the prospects for professional development (21\%).

More than $95 \%$ of respondents state their readiness to make adequate use of proven digital educational resources and technologies in the educational process. It is extremely important that today, more than $50 \%$ of teaching staff show a well-expressed professional interest in solving new problems in the field of digital education, i.e. problems of expertise, design, instruction, and training.

\section{Discussion}

This is fully explained by A. Schleicher, Director for the Directorate of Education and Skills of the Organization for Economic Co-operation and Development (OECD): "what distinguishes the approach of the city of Moscow is ... the architecture of support and incentives that have shifted the role of teachers, making them from consumers of educational services to designers and co-creators of educational content" [21].

The correlation obtained by the authors in the early 21 st century between data about the attitude of teachers to the idea of digitalization of education as a global innovation and classification of educational innovation proposed by the researcher K. Angelovsky in the late 20th century is of particular interest. Within this classification, the researcher identified groups of teachers at the end of the last century having different ideas concerning innovations.

The first group called innovators included creators of innovations, whose number at the end of the 20th century was just $7 \%$; the second group of leaders were those who used proven innovations (45\%); in the third group named moderate were those waiting for the results of extensive testing (18\%); the fourth group of the penultimate, who perceived new under the influence of a majority of colleagues who had already involved in innovation (10\%); and finally, the fifth group of teachers made up the lasts to become involved in innovations under the pressure of the administration (20\%) [22].

Relying on Angelovsky's classification in the framework of the research dealing with the issue of readiness of contemporary teachers to implement the innovative idea of digitalization of education in their professional activities allows drawing certain conclusions. Today, a quarter of a century later, the group of leaders includes $95 \%$ of respondents. These are teachers, active users of digital educational resources, who can make a competent choice of recommended digital educational resources and technologies, and use them adequately in their professional activities. While $50 \%$ of respondents who have successful professional experience in creating and applying their own original digital educational resources in the educational process receive the status of innovators in the field of digitalization of education.

\section{Conclusion}

The data obtained allow drawing the following conclusions. While in 2018 researchers (T.I. Zinovyeva, J.V. Afanasieva, A.V. Bogdanova) stated that "there has been a positive trend towards the adoption of innovations by teachers" [19, p. 123], today one can state that the Moscow education system has been already updated in terms of its digitalization. This concerns training of teaching staff, who are competent in the field of digital education; acquiring a positive experience of using ready-made digital educational resources by 
teachers, majority of whom can develop digital educational and methodological support for the educational process, and are aware of the need to build a personal trajectory of professional development within the framework of digital education.

\section{References}

1. G. Siemens, International Journal of Instructional Technology and Distance Learning 2(1) (2005). Available at: https://lidtfoundations.pressbooks.com/chapter/connectivism-a-learning-theory-for-thedigital-age/

2. J. Amin, International Journal of Indian Psychology 3(6), 40-45 (2016)

3. P. Gilster, Digital literacy (Wiley Computer Pub, New York, 1997)

4. N. Johnson, G. Veletsianos, J. Seaman, Online Learning Journal 24(2) 6-21 (2020)

5. A. Hidalgo, S. Gabaly, G. Morales-Alonso, A. Urueña, Technological Forecasting and Social Change 150 (2020)

6. V.G. Khalin, G.V. Chernova, Administrative Consulting 10, 46-63 (2018)

7. E. Reyes-Fournier, E. J. Cumella, G. Blackman, M. March, J. Pedersen, Online Learning Journal 24(2), 111-127 (2020)

8. J.W. Richardson, E. Hollis, M. Pritchard, J.E.M. Lingat, Online Learning Journal 24(1), 67-91 (2020).

9. C.J. Asarta, J.R. Schmidt, The Internet and Higher Education 44, (2020)

10. F. Martin, A. Ritzhaupt, S. Kumar, K. Budhrani, Internet and Higher Education 42, 3443 (2019)

11. G. Polizzi, Computers and Education 152, (2020)

12. I. Blau, T. Shamir-Inbal, O. Avdiel, The Internet and Higher Education 45, (2020)

13. D. Hillmayr, L. Ziernwald, F. Reinhold, S.I. Hofer, K.M. Reiss, Computers and Education 153, (2020)

14. Decree of the President of the Russian Federation № 203. Strategy for the development of the information society in the Russian Federation for 2017-2030, May 9 (2017) Available at: http://kremlin.ru/acts/bank/41919

15. Passport of the national programme "Digital economy of the Russian Federation": Protocol 16 of the Presidium of Council at the President of the Russian Federation for strategic development and national projects, December 24 (2018) Available at: http://static.government.ru/media/files/urKHm0gTPPnzJlaKw3M5cNLo6gczMkPF.pdf

16. E.K. Samerkhanova, E.P. Krupoderova, K.R. Krupoderova, L.N. Bakhtiyarova, A.V. Ponachugin, T.I. Kanyanina, Journal of Entrepreneurship Education 20(3), 1-9 (2017)

17. M. Prensky, Innovate: Journal of Online Education 5(3), 1-11 (2009)

18. M.E. Ociseanu, Procedia - Social and Behavioral Sciences 180, 1137-1144 (2015)

19. T.I. Zinovieva, J.V. Afanasieva, A.V. Bogdanova, Education in Nizhny Novgorod 3, 121-127 (2018)

20. T.I. Zinovieva, J.V. Afanasieva, A.V. Bogdanova, Education in Nizhny Novgorod 2, 19-27 (2019).

21. A. Schleicher, Building a learning culture for the digital world: lessons from Moscow Available at: https://oecdedutoday.com/learning-digital-world-technology-educationmoscow/ 
22. T.I. Zinovyeva, Journal of Secondary Vocational Education 8, 8-11 (2016) 